\title{
The development of gender assignment and agreement in English-Greek and German-Greek bilingual children
}

\author{
Maria Kaltsa, Ianthi Maria Tsimpli and Froso Argyri \\ Aristotle University of Thessaloniki / University of Cambridge / University \\ College London
}

\begin{abstract}
The aim of this experimental study is to examine the development of Greek gender in bilingual English-Greek and German-Greek children. Four gender production tasks were designed, two targeting gender assignment eliciting determiners and two targeting gender agreement eliciting predicate adjectives for real and novel nouns. Participant performance was assessed in relation to whether the 'other' language was a gender language or not (English vs. German) along with the role of the bilinguals' Greek vocabulary knowledge and language input. The results are argued to contribute significantly to disentangling the role of crosslinguistic influence in gender assignment and agreement by bringing together a variety of input measures such as early and current amount of exposure to Greek, the role of area of residence (i.e. whether Greek is the minority or the majority language), the effect of maternal education and the amount of exposure to Greek in a school setting.
\end{abstract}

Keywords: Greek gender, crosslinguistic influence, input measures, vocabulary

\section{Introduction}

This study investigates the development of gender assignment and agreement in bilingual English-Greek ${ }^{1}$ and German-Greek children by examining the role of a (non) grammatical gender language (English and German respectively), their

1. Throughout the paper, we use the terms 'English-Greek' \& 'German-Greek' bilinguals since the majority of our participants either grow up with two L1s or with English or German as their L1 up to the age of 3 (in terms of order of acquisition). Thus, when referring to ' $\mathrm{L} 1$ effects' we will be discussing the crosslinguistic influence from English/German to Greek. 
vocabulary development, age of onset of first exposure to Greek and input related factors such as home language preferences, early and current (bi)-literacy practices and oral use of Greek. Gender is realized within the DP in Greek and German. English allows gender distinctions only within its pronoun system. In grammatical gender languages, gender is a lexical property of the noun and, thus, gender is assigned in the lexicon, while determiners and adjectives acquire a gender value through agreement with the noun (Chomsky, 1995; Carstens, 2000, Tsimpli, 2014; Tsimpli \& Hulk, 2013). Drawing on data from gender assignment/agreement with real and novel nouns, this experimental study addresses the role of (a) crosslinguistic effects (English vs. German) in the acquisition of gender in a language that grammaticalizes gender (Greek), (b) proficiency in Greek (as measured through expressive vocabulary) and (c) the current type of input a bilingual child receives.

Section 2 reviews studies on bilingual gender acquisition, with emphasis on those examining gender. The gender system in Greek and German and research on monolingual child acquisition of gender in each language are also presented. In Section 3, we outline our research questions and in Section 4 we include the participants' profile and the method. Section 5 presents the results of our study, while in Section 6 we discuss our findings. Section 7 forwards conclusions.

\section{Acquisition of gender in bilingual children}

The literature on the development of gender in child bilinguals has focused on two main areas of research, crosslinguistic influence and input effects. The term 'child bilinguals' is used in this study as a general term referring to children who are exposed to two languages in early or late childhood. Thus, the term child bilinguals includes children exposed to two languages from birth (i.e. simultaneous bilinguals) and those who are exposed to a second language later in childhood (i.e. sequential bilinguals). Studies in child bilingualism have reported the existence of crosslinguistic influence from one language to another, that is subject to restrictions of directionality and/or language domain (see Paradis \& Genesee 1996; Döpke, 1998; Müller, 1998; Yip \& Matthews, 2000; Müller \& Hulk, 2001; Argyri \& Sorace, 2007; among others). The focus of recent studies, therefore, has shifted to more refined questions about the conditions that allow the interaction between the two linguistic systems of bilingual children.

2. Child bilingualism has received a number of definitions in the literature ranging from Bloomfield's (1933) claim that a bilingual has full fluency in two languages to Grosjean's (1989) suggestion that a bilingual is someone who can function in two languages for a variety of circumstances. For a thorough discussion of definitions and research limitations see Bialystok (2001). 
Gender is a parameterized option realized only in some languages, and thus, it offers two types of acquisition outcomes; outcomes in the grammar (gender agreement) and in the lexicon (gender assignment). Positive crosslinguistic influence in the form of accelerated development in one of the bilinguals' two languages (when compared with their monolingual peers) is reported in a number of gender studies (see Kupisch, 2005; Kupisch, 2007). Specifically, data from German-French ${ }^{3}$ and German-Italian simultaneous child bilinguals show that the simultaneous acquisition of a grammatical gender language like Italian accelerates the acquisition of gender marking in the other language, namely German (Kupisch, 2005). Similar findings are reported in a later study (Kupisch, 2007) on German-Italian bilingual children; Italian was again shown to positively influence the development of gender marking in German DPs with bilingual children showing lower determiner omission rates than monolingual German children.

However, the majority of studies have been mostly focusing on the role of the input rather than crosslinguistic influence itself (see Cornips \& Hulk, 2006) and that is what we attempt to address with our study by examining two language pairs, gendered/non-gendered languages and gendered-gendered languages, Greek-English and Greek-German respectively, the combinations of which have not been examined in the literature before. Thus, one of our main contributions is the disentanglement of the role of a (non-)grammatical gender language in the bilingual development of gender in the other grammatical gender language, in our case Greek.

The quantitative and qualitative properties of input have been related to the acquisition of lexical and grammatical features such as gender. Specifically, although bilingual children have to divide their language input between two languages they, nevertheless, follow the same developmental steps as monolingual children (see Paradis \& Genesee, 1996; Genesee \& Nicoladis, 2007). Input quantity has been used to measure (a) variation in vocabulary development (Cobo-Lewis et al., 2002), (b) variation in other grammatical phenomena (for verbs see Austin, 2009; Blom, 2010; Paradis, 2010; Paradis, 2011; Paradis et al., 2011; for the mass/ count distinction see Gathercole, 2002a; for grammatical gender see Gathercole, 2002b; Montrul \& Potowski, 2007) and (c) variation in the overall development of grammatical abilities (Chondrogianni \& Marinis, 2011; Jia \& Aaronson, 2003; Jia \& Fuse, 2007). Meanwhile, findings on the role of home language use suggest either a positive effect of the extensive use of the minority or weaker language at home (De Houwer, 2007; La Morgia, 2011), or no such effect at all (Goldberg et al.,

3. Kupisch (2005) notes in relation to the German-French bilingual corpus data that $\mathrm{L} 1$ transfer is evident only for contexts in which the languages' grammatical properties overlap and not for the instances where they differ. 
2008; Paradis, 2011). Recent work has shown that the small effect of a weaker language as a home language on the development of this language relates mostly to the small number of different people speaking the particular language to the child (Place \& Hoff, 2011).

An additional factor correlating positively with the amount and type of language exposure available to children is parental SES, often measured in terms of parental education (for an overview in L1, see Hoff, 2006; for bilingual development see Oller \& Eilers, 2002; Paradis, 2011; Armon-Lotem et al., 2011). Particularly, maternal educational background has been identified as a significant predictor in the development of language learning and, thus, we included it as a variable in our study (see Blair et al., 2011; Rhoades et al., 2011 among others). Earlier studies (Hoff-Ginsberg, 1991; Bradley \& Corwyn, 2002) identify a close relation between high parental SES and better language outcomes. Locke et al. (2002) and Qi et al. (2006) showed that both receptive and expressive language skills appear to be affected by SES in L1 development. In bilinguals, on the other hand, parental SES appears to contribute significantly but at the same time independently of bilingualism itself (for a detailed analysis see Calvo \& Bialystok, 2014; for the interaction of SES and literacy development in L1 and L2 see Lindholm-Leary, 2014). Consequently and unlike previous studies on gender which primarily report overall language outcomes rather than grammatical development per se we included maternal educational background as a factor to determine its contribution to the development of gender.

Additionally, age of onset has been identified as a contributing factor to the development of gender. Earlier studies on gender development show that even though simultaneous bilingual children might show a delay in development compared to monolingual children, they nevertheless appear to make the same types of errors as monolinguals even if their development is slightly slower, at least in one of their two languages (De Houwer, 1990; Müller, 1990; Kupisch et al., 2002). Other findings show that instead of a delay, bilinguals might even show acceleration in development in one of their L1s (Cornips \& Hulk, 2006). On gender specifically, Meisel's (2009) data suggest that simultaneous bilingual children performed significantly better in gender marking than L2 learners (children with first exposure to French at the age of 3;7 or later). Similar findings are reported by Carroll (1989) who identifies the age of 5 as critical to the acquisition of gender in the L2, when the L1 does not instantiate gender. Furthermore, recent elicited gender production data from Unsworth, Argyri, Cornips, Hulk, Sorace \& Tsimpli (2014) showed that gender agreement errors are found in sequential bilinguals but simultaneous bilingual children perform similar to monolinguals. These studies highlight that the age of onset and the parameterization or not of gender in 
the languages being acquired are crucial in the discussion of bilingual gender development (Meisel, 2009).

On the other hand, Montrul et al. (2008) have suggested that restricted amount of input, even if age of onset of bilingualism is from birth, may lead to gender marking errors similar to those attested in L2 adults. Gathercole (2002b) examined the identification of mismatched gender marking in Spanish DPs and reported that the children with the least input took the longest to acquire gender marking. The literature indeed distinguishes among early and current amount of exposure and the amount of exposure over time. Amount of current exposure (i.e. current percentage of regular language exposure in the target language) and amount of exposure over time (i.e. length of exposure to the target language) are identified as significant predictors for children's development of gender, while the amount of exposure in the early years (preschool age) is not as strong a predictor (Gathercole \& Thomas, 2005; Unsworth et al., 2011; Unsworth, 2013).

Another factor interacting but not identical to proficiency in bilingual acquisition is language dominance. A number of language measures have been proposed as appropriate to determine dominance (Yip \& Matthews, 2006; Cantone et al., 2008; Montrul, 2016; Silva-Corvalán \& Treffers-Daller, 2016). Kupisch (2007) uses proficiency as an indicator of dominance, while Unsworth (2016) employs the amount of exposure to each language as a proxy for dominance. In our study, balance and dominance are measured in terms of the distance between the vocabulary scores of the two languages of the bilingual child. The resulting score will be used as an independent variable whose role on gender performance will be examined independently from the variable of proficiency.

Considering the diverse findings on crosslinguistic influence and the role of input in gender development the present study contributes significantly to the literature with a large cross-sectional dataset ${ }^{4}$ (102 bilingual and 35 monolingual children) testing (a) the role of Greek vocabulary skills and vocabulary dominance in the production of gender and (b) crosslinguistic influence in terms of the effect of a gendered language (German) vs. a non-gendered language (English) in the development of gender in Greek. Additionally, since the amount of language exposure has previously been found to affect the linguistic development of bilingual children, the present study attempts to identify the input measures that best predict the acquisition of gender by focusing on current use of Greek as well as use of Greek during preschool years, the role of area of residence (i.e. in terms of whether Greek is the minority or majority language), the amount of hours of classroom instruction in Greek and, finally, the role of maternal educational background as

4. The original dataset included data from 165 bilingual and 57 monolingual children aged 8 to 12 years old. However, in the present write-up only the 10 to 12 year old data are reported. 
a proxy for SES. Input is therefore measured both in terms of amount of current exposure to the language on the basis of the individual profile of the child but also in terms of the majority/minority language difference, exposure in the early years, and structured exposure in instruction settings. As such the study provides a detailed input measures profile for each child in addition to age of onset and SES measures. Crucially, for school age bilingual children, like the participants of our study, structured input in the form of literacy exposure in each language is of primary importance as written language and school settings take up the majority of the child's daily schedule.

\subsection{Greek gender}

There is a three- or two-way gender distinction across gendered languages, that is masculine, feminine or neuter (Corbett, 1991). We assume that in languages with grammatical gender, gender is a lexical feature (cf. Chomsky, 1995) classifying nouns while gender agreement is a syntactic operation that involves a dependency between an uninterpretable (or unvalued) feature on D or Adj and its valued counterpart on N (Chomsky, 2001; Carstens, 2000; Bošković, 2009a, 2009b). Following Bošković (2009a, 2009b) we assume that unvalued rather than uninterpretable features drive syntactic operations and that multiple checking of gender features in the Determiner Phrase (DP) is possible (cf. Carstens 2000). Nouns are intrinsically marked for a valued, uninterpretable gender feature and the gender agreement relation is probed by the unvalued and uninterpretable gender feature (on Determiner or Adjective) targeting the valued one on the Noun (see Tsimpli \& Hulk, 2013 for a detailed account).

For Greek, Ralli (2002) suggests a three-way gender distinction with gender being a feature of the noun stem, while the suffix only spells-out the gender value of the stem (cf. Tsimpli, 2003; Hawkins \& Tsimpli, 2009). The gender feature establishes gender agreement in syntax:

(1) o oréos kírios

$$
\text { the }_{\text {MASC }} \text { nice }_{\text {MASC }} \text { man }_{\text {MASC }}
$$

(2) i mejáli bála

$$
\text { the } \mathrm{FEM}_{\mathrm{FEM}} \text { big }_{\mathrm{FEM}} \text { ball }_{\mathrm{FEM}}
$$

(3) to yemáto potíri

$$
\text { the } \text { NEUT }_{\text {full }} \text { NEUT }_{\text {moon }} \text { NEUT }
$$

Previous studies on the acquisition of Greek suggest that monolinguals acquire gender by age 3;6 or even earlier (cf. Stephany, 1997; Marinis, 2003; Mastropavlou, 2006; Stephany \& Christofidou, 2008). Neuter gender is the default value (Tsimpli 
\& Hulk, 2013) imposing the lowest learnability load to the learner (Stephany, 1997) and the preferred one by young monolinguals (Mastropavlou, 2006) and L2 learners of Greek (Varlokosta, 1995; Tsimpli, 2003; Konta, 2013). The role of noun endings in the elicited production of gender agreement with novel nouns has also been shown to be decisive in monolingual development albeit not from the earliest production stage of gender acquisition of real nouns. In particular, both Mastropavlou (2006) and Varlokosta (2011) report that 3 and 5-year old monolingual Greek children respectively show more accurate gender assignment with noun endings of high predictive values than with those of $l o w^{5}$ predictive values. The difference, however, between high and low predictive values in gender production was significant in the 5-year-old group but not in the 3 -year-old group (Mastropavlou, 2006). Thus, phonological cues on noun endings and their predictive values appear to have an effect on gender assignment on novel nouns later than lexical knowledge of gender on real nouns. This finding suggests that the learner sensitivity to noun endings presupposes a certain length of exposure for predictive values to develop (for the predictive values of suffixes for Greek adults see Mastropavlou \& Tsimpli, 2011). In view of the monolingual findings and the delay in the role of noun endings vs. lexical gender in the acquisition of gender assignment and gender agreement on novel and real nouns respectively, bilingual performance on real and novel nouns is expected to reflect input differences required for the two categories. By focusing on the comparison between real and novel noun gender in bilingual children we can distinguish between the role of vocabulary skills and other measures of input which are expected to differentially affect gender acquisition on real and novel nouns respectively.

\subsection{German gender}

German, similarly to Greek, has a three-way gender distinction of masculine, feminine and neuter which is marked on different types of determiners, pronouns and attributive adjectives (Bauch, 1971). Some degree of syncretism is found however, as in the examples below where the form of the indefinite article is the same for masculine and neuter (from Kupisch et al., 2013: 157):

(4) ein interessanter Film an $_{\text {MASC/NEUT }}$ interesting MASC $_{\text {film }}$ MASC

(5) eine interessante Zeitung an $_{\mathrm{FEM}}$ interesting FEM $_{\text {newspaper }}$ FEM

5. Note that for certain suffixes such as $-i$, the orthographic cues indicate the appropriate gender. 
(6) ein interessantes Buch

an $_{\text {MASC/NEUT }}$ intersting ${ }_{\text {NEUT }}$ book $_{\text {NEUT }}$

Unlike in Greek, attributive adjectives in definite DPs (with the exception of accusative singular) and predicate adjectives do not show gender distinctions, as illustrated in examples (7) to (12) respectively (Kupisch, Akpinar \& Stöhr, 2013: 157):

$\begin{array}{ll}\text { (7) der interessante } & \text { Film } \\ \text { the }_{\text {MASC }} \text { interesting } & \text { film } \\ \text { MASC/FEM/NEUT }\end{array}$

(8) die interessante Zeitung

the $_{\text {FEM }}$ interesting MASC/FEM/NEUT $_{\text {newspaper }}$ FEM

(9) das interessante Buch

the $_{\text {NEUT }}$ intersting MASC/FEM/NEUT $_{\text {book }}$ NEUT

(10) Der Film ist interessant.

The $_{\text {MASC }}$ film $_{\text {MASC }}$ is intersting MASC/FEM/NEUT

(11) Die Zeitung ist interessant.

The $_{\mathrm{FEM}}$ newspaper $_{\mathrm{FEM}}$ is intersting $\mathrm{MASC} / \mathrm{FEM} / \mathrm{NEUT}$

(12) Das Buch ist interessant.

The $_{\text {NEUT }}$ book $_{\text {NEUT }}$ is intersting ${ }_{\text {MASC/FEM/NEUT }}$

With regard to gender assignment, the gender value may be predicted on the basis of semantic and morphophonological factors (Lang, 1976; Köpcke, 1982; Corbett, 1991). Most of these factors, however, are not deterministic rules but are of a probabilistic nature, in the sense that there is a tendency for nouns exhibiting a particular phonological, morphological pattern or belonging to a certain semantic domain to be associated with a particular gender (Szagun, Stumper, Sondag \& Franik, 2007). An example of semantically-based gender assignment is that nouns denoting weather, birds and beverages tend to be masculine, whereas nouns denoting trees, flowers, knowledge and crafts, tend to be feminine (see Hoeppner, 1980; Szagun et al., 2007). Needless to say, such generalizations can only be derived once sufficient members of each semantic category are already acquired and the learner can, at some stage of development, abstract the appropriate semantic category. Finally, gender distinctions in German, as in Greek, are also exhibited by morphosyntactic cues as in the different forms of definite articles. Such cues are sufficiently robust for the learner to use in the discovery of particular gender values.

The production of gender mismatches between determiner and noun drops significantly around the age of 3 for monolingual German speaking children suggesting sensitivity to gender assignment rules from an early age (Mills, 1986; Müller, 1990; Szagun et al., 2007). However, gender errors with neuter nouns are attested beyond 
this age and these difficulties are attributed to the complexity of the German gender system in the sense that gender, case and number marking overlap (see Müller, 1987; Müller 1990; Jansen 2009; Eichler, Jansen \& Müller, 2012). German, like Greek, marks gender, case and number on (singular) articles, for example, the definite article 'der': masculine, singular, nominative. As a result, some forms are syncretic; for example, the definite article 'der' is used for nominative masculine and dative feminine (Szagun et al., 2007). Gender marking in German is, thus, considered to be complex and not transparent from the child's perspective leading to difficulties in gender acquisition (Eichler et al., 2012). Bilingual acquisition data also show high sensitivity to gender cues from an early age, prior or up to the age of 3 with differences to monolinguals being predominantly of a quantitative nature rather than qualitative one (Kupisch et al., 2002; Kuchenbrandt, 2005; Eichler et al., 2012). Also, differences in acquisition are found with regard to definite and indefinite article-noun mismatches with indefinite ones showing lower accuracy scores for simultaneous bilinguals (Müller, 1990; Kupisch et al., 2002). In sum, monolingual and bilingual data on the acquisition of gender in German appears to be sensitive to gender cues and number of morpho-semantic variables appear to affect performance.

\section{Research questions}

Having outlined the relevant formal properties of gender in the languages involved, namely Greek and German, and considering the developmental findings for bilinguals, the research questions of our study are the following:

i. What is the role of the bilingual children's other language in the acquisition of Greek gender? Does German, a grammatical gender language, accelerate gender development in Greek compared to the English-Greek bilingual combination? Does the other language affect gender marking in Greek even when language proficiency (as measured by expressive vocabulary scores) is controlled for?

ii. What are the differences between gender assignment (Determiner-Noun) and gender agreement (Noun-Adjective) in real and novel noun contexts? Does accuracy on real (lexical gender) and novel nouns (predictive value of the noun suffix) differ in bilinguals?

iii. Which of the Greek input measures can best predict gender accuracy in assignment and gender agreement tasks? Is it amount of early exposure to Greek, current use of the language, area of residence (minority or majority language status) or formal instruction in Greek that can best predict gender accuracy? Does vocabulary development as an indirect measure of input correlate with gender accuracy? 


\section{Method}

\subsection{Participants and background variables}

The participants were 102 bilingual children from 10;0 to 12;0 years of age. There were 52 English-Greek bilinguals (22 girls) and 50 German-Greek bilinguals (25 girls). The English-Greek group had a mean age of $11 ; 3$ (SD:0;7) and the GermanGreek group had a mean age of 11;4 (SD: 0;7). Data was also collected from 35 Greek monolingual children who attended a state primary school in Northern Greece (20 girls) and had a mean age of $11 ; 1$ (SD: 0;5, age range: 10;0 to 12;0). There was no significant difference in age between the bilingual and monolingual groups $\left.F(2,135)=1.38, p>.05, \eta_{\mathrm{p}}{ }^{2}=.039\right) .{ }^{6}$ All participants in the study were typically developing without any history of speech and/or language disorder.

The bilingual participants were located either in Greece or abroad (UK/USA and Germany respectively). The English-Greek bilinguals in Greece ( $N: 37)$ attended a private international school, where the hours of instruction in Greek ranged between 5 and 10 hours per week and the hours of instruction in English were between 25 and 30. The English-Greek bilinguals in the UK $(N: 7)$ attended monolingual English schools and either a weekly afternoon or a Saturday class of L2 Greek instruction. The English-Greek bilinguals in the USA ( $N: 8)$ attended a bilingual school, where the hours of instruction in Greek were 10 per week and the hours of instruction in English were between 25 and 30 hours. The GermanGreek bilinguals in Greece ( $N: 20)$ attended a private bilingual school, where the hours of instruction in Greek per week ranged between 4 and 7 and the hours of instruction in German were between 19 and 25. The German-Greek bilinguals in Germany ( $N: 30)$ attended a variety of school settings, where the hours of instruction in Greek per week ranged between 8 and 21 hours and the hours of instruction in German between 9 and 20.

Background information was collected on a number of input related variables with the use of questionnaires administered to parents and to children. These questionnaires were developed by Mattheoudakis, Chatzidaki and Maligkoudi (2014) for the purposes of a larger project in which the present study is situated. Questionnaires included a variety of questions with regard to the acquisition of each language, family practices in the pre-school age and at the time of testing along with information on formal instruction in the L1 and L2. The questionnaire information is presented in Table 1 below:

6. For effect sizes, we follow Cohen (1988) according to who values $0.01,0.06$ and 0.14 for $\eta^{2}$ are reported as small, medium and large effect sizes respectively. 
Table 1. Background information of bilingual participants

\begin{tabular}{llll}
\hline & & English-Greek bilinguals & German-Greek bilinguals \\
\hline Age of onset (Greek) & from birth & $54 \%{ }^{*}$ & $12 \%$ \\
& $3-6$ yrs & $36.5 \%$ & $54 \%$ \\
& $6+$ yrs & $9.5 \%$ & $34 \%$ \\
Home language - Greek & $46 \%{ }^{* *}(\mathrm{SD}: 18)$ & $57 \%(\mathrm{SD}: 18)$ \\
Early literacy - Greek & $45 \%(\mathrm{SD}: 27)$ & $60 \%$ (SD:36) \\
Current literacy - Greek & $15 \%(\mathrm{SD}: 9)$ & $30 \%$ (SD:16) \\
Current language use - Greek & $31 \%(\mathrm{SD}: 15)$ & $44 \%$ (SD: 17$)$ \\
Maternal education (scale: $1-5)$ & $4.9(\mathrm{SD}: 0.2)$ & 3.6 (SD:1.3)
\end{tabular}

Notes * For the Age of Onset measure, the Table reports the distribution of the bilingual participants in the three categories; simultaneous (from birth), early-sequential (i.e. exposure to Greek between the ages of 3-6 years) and late-sequential (6+ years old).

** For the input measures Home Language, Early Literacy, Current Literacy and Current Language Use the table reports the frequency of use of Greek by the bilinguals.

Starting with age of onset and types of bilingualism, following Meisel (2009) three different groups were formed: from birth up to age 3 were the group of simultaneous bilinguals, from age 3 to age 6 were the early sequential bilinguals and from age 6 onwards the late sequential bilinguals. To determine age of onset, the questionnaire included a question about the child's country of birth, a question about age of arrival to Greece if not born in the country and if the family has relocated along with family practice questions regarding language use during the preschool age (from birth up to the age of 6). The distribution of participants differs in the language groups $\left(F(1,101)=25.75, p<.001, \eta_{\mathrm{p}}{ }^{2}=.038\right)$ as there are significantly more simultaneous bilinguals in the English-Greek group and early sequential bilinguals in the German-Greek group.

Home Language refers to the children's exposure to each language from birth up to the age of schooling. The relevant questions collected information about the language(s) the child heard/used from birth up to the age 6 with a variety of speakers (parents, siblings, extended family and friends). Despite the differences in the order of acquisition of Greek and the small number of German-Greek in the simultaneous bilinguals category (exposure to Greek from birth up to the age of 3), the two bilingual groups differed in the degree Greek was used as a home language up to the age of 6 with German-Greek bilinguals being exposed to Greek more extensively $\left(F(1,101)=7.44, p=.008, \eta_{\mathrm{p}}{ }^{2}=.044\right)$ suggesting that family practices in German-Greek homes systematically backed the development of Greek during the pre-school years.

The Early Literacy measure concerns the degree to which Greek was used when family members read books to children up to the age of 6 (shared book reading). 
Specifically, they were asked if and how often they would read books to children and in which language they would choose to do so. Data showed that shared book reading in the Greek medium was mostly preferred by German-Greek bilingual families $\left(F(1,101)=4.53, p=.036, \eta_{\mathrm{p}}^{2}=.037\right)$. The Current Literacy measure aims to evaluate children's current language preference/use in writing/reading tasks, and, more specifically the degree to which they preferred to use Greek for daily writing/reading tasks (writing lists/letters/cards, reading aloud, texting, emailing, visiting websites, video-gaming, book/magazine reading). As shown in Table 1, the English-Greek bilinguals would use Greek less frequently than the GermanGreek bilinguals $\left(F(1,101)=27.85, p<.001, \eta_{\mathrm{p}}{ }^{2}=.027\right)$.

Lastly, the Current Language Use measure concerns the participants' daily language preference/use in oral tasks. The questionnaires asked about the children's preferred language for oral interaction with family members/friends, for memorizing phone numbers, telling the time, mental counting/calculating, watching TV/ movies. The frequency of use of Greek for their oral activities was shown to differ in the two language groups with German-Greek bilinguals using Greek about half of the time $\left(F(1,101)=13.80, p<.001, \eta_{\mathrm{p}}{ }^{2}=.115\right)$ in contrast to the English-Greek bilingual children. This study also investigated the role of the Socioeconomic Status (SES) measured in terms of maternal educational background. An ordinal scale from 1 to 5 with " 1 "assigned to primary education and " 5 " to university education was used. The maternal education of the two language groups was statistically different with the English-Greek group having a higher score as shown in Table 1 $\left(F(1,101)=38.24, p<.001, \eta_{\mathrm{p}}{ }^{2}=.095\right)$. Note, however, that both groups have high SES scores corresponding to the educational background of college (4) or university (5) in contrast to earlier studies who tested speakers with predominantly low SES (Hoff-Ginsberg, 1991; Bradley \& Corwyn, 2002; Calvo \& Bialystok, 2014).

The children's lexical abilities were measured by means of standardized expressive vocabulary tests in Greek (Vogindroukas et al., 2009), in English (Renfrew, 2001) and in German (Peterman, 2010). In each vocabulary task, the participant was asked to name a depicted item provided in black and white pictures. The Greek and the English vocabulary tasks consisted of 50 items each and the German one of 40 items. The participants' vocabulary scores were used as independent measures of language proficiency in Greek and in English/German and are presented in Table 2: 
Table 2. Bilinguals' language proficiency

\begin{tabular}{lll}
\hline & English-Greek bilinguals & German-Greek bilinguals \\
\hline Greek Vocabulary & $58 \%$ (SD:22) & $60 \%$ (SD:22) \\
& [Range: 32\%-96\%] & [Range: 30\%-96\%] \\
Other Vocabulary (English \& German & $84 \%$ (SD:9) & $75 \%$ (SD:16) \\
respectively) & [Range: 66\%-100\%] & [Range: 52\%-97\%] \\
\hline
\end{tabular}

Between-group comparisons showed that neither the development of Greek vocabulary nor the development of the other vocabulary (English/German) differed between the two language groups. Within-group comparisons revealed that for both groups vocabulary scores in English and German were significantly higher than in Greek (English-Greek bilinguals: $F(1,51)=38.91, p<.001, \eta_{\mathrm{p}}{ }^{2}=.146$; Greek-German bilinguals: $\left.F(1,49)=43.17, p<.001, \eta_{\mathrm{p}}^{2}=.159\right)$.

Lastly, to determine language dominance we compared the size of each vocabulary for each bilingual. To this end, we turned vocabulary test scores into $\mathrm{z}$-scores ${ }^{7}$ (i.e. standard scores) and we subtracted the 'other' language's vocabulary $\mathrm{z}$-score from the Greek vocabulary $\mathrm{z}$-score; if the result was between -1 and +1 , an outcome which signifies vocabularies of comparable size, we considered the participant a balanced bilingual. If the result was higher than +1 , the participant was considered Greek dominant, while if the result was lower than -1 , then $\mathrm{s} /$ he was considered dominant in the other language. The English-Greek bilinguals are thus distributed in 54\% balanced bilinguals, 27\% Greek-dominant and 19\% English-dominant, while the German-Greek bilinguals in 54\% balanced, 13\% Greek-dominant and 28\% German-dominant; there were no statistically significant distributional differences between the two language groups.

The participants profiling covers a number of language related measures highlighting the differences in input and unveiling the variability the bilingual populations exhibit in general and in our dataset in particular. It is essential to recognize this variability in the dataset in order to address how these differences can potentially affect the performance of participants. Most studies employ one criterion to group their participants assuming largely homogeneity across bilingual populations. By bringing these differences forward (a) we are sheding light to the true characteristics of a bilingual dataset and (b) we address their role as key predictive variables in gender performance through a regression analysis that will hierarchy their potential effect on gender development. The between group comparisons that follow in sections 5.1 and 5.2 attempt to present the overall performance for the two language pairings.

7. For the use of z-scores in empirical data see Featherston \& Winkler (2009). 


\subsection{Tasks \& procedure}

To test the bilingual acquisition of grammatical gender in Greek, four elicited production tasks were designed, two targeting gender assignment and two gender agreement for real and novel nouns. For all tasks, children were presented with the pictures of the real and novel nouns in question on a computer screen and they were subsequently asked a question about the picture (PowerPoint presentation). Participants were expected to use an appropriate definite or indefinite determiner in the gender assignment tasks (Det-N), and an agreeing predicate adjective in the gender agreement tasks.

The gender assignment tasks comprised one real and one novel noun elicited production task. The real noun task included 54 test items (animals or objects). Children were initially presented with the pictures and the relevant test words (real nouns) on a computer screen in order to familiarize them with the test items. For each test item, children could see the relevant picture, hear the corresponding real noun and see the written form of the word (in order for orthographic cues to be provided). A short practice session (3 practice items) followed and then the actual testing started. For each practice/test item, children saw the picture of an object/animal on a table and heard the question 'What is on the table?', thereby eliciting a definite/indefinite determiner in a Det-N DP (The question was also presented on the computer screen). An example item for real nouns is given in (13) (masculine noun with the suffix -os) below:

$$
\begin{aligned}
& \text { a. ti íne páno sto trapézi? } \\
& \text { what be }{ }_{3 S I N G} \text { on the table } \\
& \text { 'What is on the table?' } \\
& \text { b. énas/o papagalos } \\
& a_{\text {MASC }} \text { /the } \text { MASC parrot }_{\text {MASC }} \\
& \text { 'A/the parrot.' }
\end{aligned}
$$

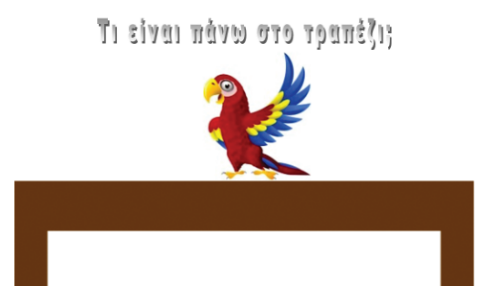

8 items were used for each of the three Greek gender values. The masculine and neuter values comprised 6 items for each of the three endings, i.e. [-as, -is, -os for masculine and $-m a,-i,-o$ for neuter], whereas the feminine value comprised 9 items for each of the two endings $[-a$ and $-i]$.

The novel word elicited production task included 56 three-syllable penultimate accented test items. The same endings were used for each gender value, with 8 items for each ending [-as, -is, -os- $a,-i$ (spelled as $\eta$, feminine nouns only) ${ }^{8}$ and $-m a,-o]$. There are 2 slides for each test item. In the first slide, children saw the

8. Note that because the phonological cue - i could be attributed both to feminine and neuter, we chose to present it only with the feminine orthographic cue. Additionally, we distributed items equally across all endings so that we do not create a gender bias, hence, the mismatch in 
picture of a novel object, heard the novel noun and saw its written form. In the second slide, children saw the novel object on a table and heard the question 'What is on the table?', thereby eliciting a definite/indefinite determiner in a Det-N DP (The question was also presented on the computer screen). An example item for novel nouns (slide 2) is given below (novel noun with the masculine suffix -is):
a. ti íne páno sto trapézi? what be ${ }_{3 \text { SING }}$ on the table 'What is on the table?'
b. énas/o krodotís $a_{\text {MASC }}$ the MASC $_{\text {krodotis }}$ MASC

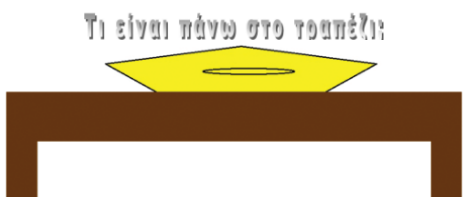

All test items corresponded to the nominative singular form, which constitutes the citation form for nouns in Greek.

The gender agreement elicited production tasks included real adjectives predicating real and novel nouns in two different tasks. The real noun task consisted of 54 test items and the novel noun task of 56 test items. The suffixes used per gender value, and the general set up were the same as in the gender assignment tasks. However, in the gender agreement tasks, the participants were presented with two pictures of the same real or novel noun in each slide. These pictures differed either in colour and/or size. Children were asked to answer the question 'What kind of $\mathrm{X}$ (test item) is it?', thereby eliciting an agreeing predicate adjective. A blue arrow was used to point to one of the pictures of the real or novel noun on the screen in order to facilitate the children's response. An example item for real nouns (masculine noun and an agreeing masculine predicate adjective with the suffix -os) is given in (15a) and an example item for novel nouns (masculine noun and an agreeing masculine predicate adjective with the suffix -os) is given in (15b):
a. ti papagalos íne? mikrós. what parrot ${ }_{\text {MASC }}$ be $_{3 S I N G}$ ? Small MASC $_{\text {S }}$ 'What kind of parrot is it? Small.'
b. ti krodotís íne? kitrinos. what krodotis MASC $_{3 \text { SING }}$ ? yellow MASC $_{\text {. }}$ 'What kind of krodotis is it? Yellow.'

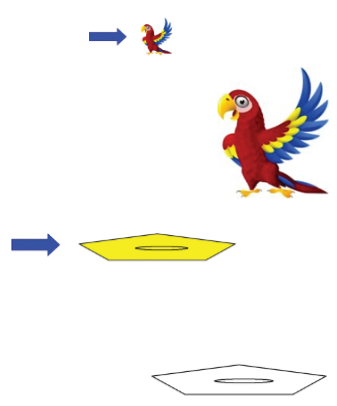

number to real noun tasks, where we equally distributed items across gender rather than noun endings for the same reason. 
All responses were transcribed and accuracy scores per participant were used in the analysis. Score 1 was assigned for each correct response and score 0 for an erroneous one. Correct responses were identified as follows: (a) in the gender assignment tasks, the use of a determiner agreeing in gender with the noun provided, and (b) in the gender agreement tasks, the use of any adjective agreeing in gender with the noun provided.

\subsection{Predictions}

The paper aims to examine the role of the L1 and input effects in the acquisition of gender assignment and agreement in real and novel nouns by bilingual children whose 'other' language may or may not be a gendered language. Considering previous research findings and the formal gender properties of the languages (Greek, English and German) involved the following predictions are proposed.

We predicted that positive crosslinguistic influence in the form of higher accuracy scores in German-Greek vs. English-Greek bilingual children would be attested. Specifically, due to the differences between German and English in grammatical gender (i.e. German encodes grammatical gender on nouns but English does not) we predicted that German-Greek bilinguals perform better on Greek gender assignment and agreement tasks compared to English-Greek bilinguals even when we control for language proficiency through the expressive vocabulary scores. Also, note that the bilinguals tested even though they differed to some degree in terms of input, they did not differ in reference to their language proficiency; as such the comparison of the language - pairs is possible.

Secondly, regarding the comparison between real and novel nouns, we formulate our predictions on the grounds that real nouns carry gender specification as part of their lexical entry, while gender on novel nouns needs to be determined on the basis of morphophonological cues on the noun's suffix. We, thus, expect performance on real nouns to be affected by lexical skills measured as vocabulary scores considerably more than on novel nouns, which should be more dependent on input measures. Moreover, we expect differences to emerge in relation to assignment vs. agreement, since the latter is more demanding due to the complexity of its structure: a predicate adjective agrees clause-internally but not locally as is the case with attributive adjectives inside the $\mathrm{DP}^{9}$. Finally, we predict that among the different input measures, those that relate to current exposure to and use of Greek such as current oral use of Greek, area or residence (minority vs. majority language) and Greek schooling are better predictors of gender accuracy than

9. On the difficulties posed by predicate adjectives as opposed to attributive adjectives also see Blom, Polišenská and Weerman (2008) and Konta (2013). 
other background measures such as age of onset of exposure to Greek and early literacy exposure.

\section{Results}

With regard to the data analysis, to control variability in our data and to disentangle crosslinguistic influence from language proficiency, we ran an ANCOVA analysis with word type (real vs. novel) and gender (masculine vs. feminine vs. neuter) as the within-group variables, group (English-Greek bilinguals vs. German-Greek bilinguals vs. Greek monolinguals) as the between-subjects factor and language proficiency (Greek vocabulary score) as the covariate (Sections 5.1 and 5.2). Next, to assess the relationship between Greek proficiency and gender accuracy we computed the Pearson product-moment correlation coefficient (Section 5.3). Lastly, to examine the role of input measures provided by the background questionnaire, we performed a stepwise regression analysis across bilinguals that provides a hierarchy of significant factors affecting performance in gender assignment and agreement in real and novel nouns (Section 5.4).

\subsection{Gender assignment}

To examine gender assignment in real and novel nouns, we analysed data from the two determiner tasks. We performed a repeated measures analysis with word type (real vs. novel) as the within-group variable, group (English-Greek bilinguals vs. German-Greek bilinguals vs. Greek monolinguals) as the between-subjects factor, and language proficiency (Greek vocabulary score) as the covariate. The total accuracy scores per task and per group are presented in Table 3:

Table 3. Total gender assignment accuracy scores (determiner tasks)

\begin{tabular}{llll}
\hline & English-Greek bilinguals & German-Greek bilinguals & Monolinguals \\
\hline Real Nouns & $83 \%(\mathrm{SD}: 17)$ & $86 \%(\mathrm{SD}: 15)$ & $99 \%(\mathrm{SD}: 3)$ \\
Novel Nouns & $71 \%(\mathrm{SD}: 22)$ & $81 \%(\mathrm{SD}: 15)$ & $86 \%(\mathrm{SD}: 7)$ \\
\hline
\end{tabular}

The statistical analysis shows a main effect of word type with real nouns showing higher accuracy scores compared to novel nouns $(F(1,133)=7.54, p=.007$, $\eta_{\mathrm{p}}{ }^{2}=.054$, real $>$ novel: $\left.p<.001\right)$ and a main effect of group $(F(2,133)=13.45$, $\left.p<.001, \eta_{\mathrm{p}}^{2}=.168\right)$ with monolingual children and German-Greek bilinguals performing alike and scoring significantly higher compared to English-Greek bilinguals (both pair comparisons $p<.001$ ). Moreover, the data show an interaction of word type and group variables $\left(F(2,133)=4.48, p=.013, \eta_{\mathrm{p}}^{2}=.063\right)$. 
Next we examine the differences in accuracy for masculine, feminine and neuter items (see Table 4 for accuracy scores for real and novel items) using a repeated measures analysis with word type ${ }^{10}$ (real vs. novel) and gender (masculine vs. feminine vs. neuter) as the within-group variables, group (English-Greek bilinguals vs. German-Greek bilinguals vs. Greek monolinguals) as the betweensubjects factor and language proficiency (Greek vocabulary score) as the covariate.

Table 4. Gender assignment: accuracy scores per gender (determiner tasks)

\begin{tabular}{lllc}
\hline Nouns & English-Greek bilinguals & German-Greek bilinguals & Monolinguals \\
\hline Masc Real & $79 \%(\mathrm{SD}: 27)$ & $86 \%(\mathrm{SD}: 22)$ & $100 \%(\mathrm{SD}: 1)$ \\
Masc Novel & $76 \%(\mathrm{SD}: 34)$ & $87 \%(\mathrm{SD}: 25)$ & $99 \%(\mathrm{SD}: 2)$ \\
Fem Real & $83 \%(\mathrm{SD}: 19)$ & $82 \%(\mathrm{SD}: 18)$ & $99 \%(\mathrm{SD}: 4)$ \\
Fem Novel & $58 \%(\mathrm{SD}: 26)$ & $57 \%(\mathrm{SD}: 17)$ & $71 \%(\mathrm{SD}: 17)$ \\
Neut Real & $86 \%(\mathrm{SD}: 14)$ & $88 \%(\mathrm{SD}: 11)$ & $99 \%(\mathrm{SD}: 4)$ \\
Neut Novel & $77 \%(\mathrm{SD}: 20)$ & $86 \%(\mathrm{SD}: 15)$ & $82 \%(\mathrm{SD}: 14)$ \\
\hline
\end{tabular}

The analysis reveals a main effect of gender $\left(F(2,133)=60.63, p<.001, \eta_{\mathrm{p}}^{2}=.313\right)$ with performance in masculine and neuter items being significantly better compared to feminine items (both pair comparisons $p<.001$ ). There is also an interaction of gender and group variables $\left(F(2,133)=5.62, p=.005, \eta_{\mathrm{p}}^{2}=.078\right)$ but no interaction of gender and word type variables or of gender, word type and group variables are identified in the data set.

The gender assignment data show there is a strong word type and gender effect with best performance in real nouns and masculine and neuter items. Moreover, even though language proficiency was controlled for the German-Greek bilingual children perform similarly to Greek monolingual children and significantly better to the English-Greek bilinguals suggesting that the L1 is indeed a factor that affects performance.

\subsection{Gender agreement}

To examine gender agreement in real and novel nouns, we analysed data from the two adjective tasks. We performed a repeated measures analysis with word type (real vs. novel) as the within-group variable, group (English-Greek bilinguals vs. German-Greek bilinguals vs. Greek monolinguals) as the between-subjects fac-

10. To avoid statistical repetition the main effect of word type is not reported again. All significant and non-significant effects and interactions appear in Appendix 2. 
tor, and language proficiency (Greek vocabulary score) as the covariate. The total accuracy scores per group in the agreement tasks are presented in Table 5:

Table 5. Total gender agreement accuracy scores (predicate adjective tasks)

\begin{tabular}{llll}
\hline & English-Greek bilinguals & German-Greek bilinguals & Monolinguals \\
\hline Real Nouns & $82 \%($ SD:24) & $88 \%$ (SD:15) & $99 \%$ (SD:2) \\
Novel Nouns & $59 \%($ SD:22) & $58 \%(S D: 21)$ & $76 \%(S D: 15)$ \\
\hline
\end{tabular}

The statistical analysis shows a main effect of word type with real nouns showing higher accuracy scores compared to novel nouns $(F(1,133)=10.39, p=.002$, $\eta_{\mathrm{p}}^{2}=.072$, real $>$ novel: $\left.p<.001\right)$ and a main effect of group $(F(2,133)=3.51$, $\left.p=.033, \eta_{\mathrm{p}}^{2}=.050\right)$ with bilinguals performing alike and scoring lower compared to monolinguals (Monolinguals $>$ English-Greek bilinguals: $p=.005$; Monolinguals $>$ German-Greek bilinguals: $p=.012$, English-Greek bilinguals $=$ German-Greek bilinguals: $p=.068)$. Moreover, the data show an interaction of word type and group variables $\left(F(2,133)=4.54, p=.012, \eta_{\mathrm{p}}{ }^{2}=.064\right)$.

Next we examine the differences in accuracy for masculine, feminine and neuter items (see Table 6 for accuracy scores for real and novel items in gender agreement) using a repeated measures analysis with word type (real vs. novel) and gender (masculine vs. feminine vs. neuter) as the within-group variables, group (English-Greek bilinguals vs. German-Greek bilinguals vs. Greek monolinguals) as the between-subjects factor and language proficiency (Greek vocabulary score) as the covariate.

Table 6. Gender agreement: Accuracy scores per gender (predicate adjective tasks)

\begin{tabular}{lllc}
\hline Nouns & English-Greek bilinguals & German-Greek bilinguals & Monolinguals \\
\hline Masc Real & $75 \%(\mathrm{SD}: 35)$ & $83 \%$ (SD:24) & $100 \%$ (SD:2) \\
Masc Novel & $58 \%(\mathrm{SD}: 39)$ & $54 \%$ (SD:35) & $80 \%$ (SD:25) \\
Fem Real & $79 \%(\mathrm{SD}: 32)$ & $85 \%(\mathrm{SD}: 21)$ & $99 \%(\mathrm{SD}: 4)$ \\
Fem Novel & $34 \%(\mathrm{SD}: 25)$ & $37 \%(\mathrm{SD}: 27)$ & $61 \%(\mathrm{SD}: 18)$ \\
Neut Real & $93 \%(\mathrm{SD}: 13)$ & $97 \%(\mathrm{SD}: 4)$ & $100 \%(\mathrm{SD}: 1)$ \\
Neut Novel & $84 \%(\mathrm{SD}: 19)$ & $84 \%(\mathrm{SD}: 17)$ & $85 \%(\mathrm{SD}: 19)$ \\
\hline
\end{tabular}

The analysis reveals a main effect of gender $\left(F(2,133)=117.42, p<.001, \eta_{\mathrm{p}}{ }^{2}=.469\right)$ with best performance in neuter followed by masculine and last by feminine items (neuter $>$ masculine $>$ feminine: all pair comparisons $p<.001$ ). There is also an interaction of gender and group variables $\left(F(2,133)=3.96, p=.021, \eta_{\mathrm{p}}^{2}=.056\right)$ and an interaction of gender and word type variables $(F(1,133)=9.50, p=.002$, $\left.\eta_{\mathrm{p}}^{2}=.067\right)$ but no interaction of gender, word type and group variables. 
The gender agreement data show that there is a strong word type effect and gender effect with best performance in real items and the highest accuracy scores in neuter items. Moreover, contrary to gender assignment data, the agreement data showed more similarities between the English-Greek and German-Greek bilinguals.

\subsection{The role of lexical skills}

As presented in Section 2.1 above, the main difference between gender cues in real and novel nouns is the knowledge that the two are expected to be drawing from: gender accuracy on real nouns draws primarily on lexical knowledge as well as sensitivity to gender cues offered by the noun. For novel nouns, lexical knowledge is only indirectly relevant as novel nouns build on generalizations based on language exposure which allows the learner to assign probabilistic values on noun endings. Thus, the weighting of lexical knowledge is expected to be different for real and novel nouns. We thus predicted that gender marking on real nouns strongly correlates to language proficiency measured with the expressive vocabulary task. In contrast, we predicted that novel nouns would not show as strong a correlation. The Pearson product-moment correlation coefficient was computed to assess the relationship between the Greek vocabulary scores in the Vogindroukas et al. (2009) task and gender assignment (determiner) and agreement (adjective) scores in the real and novel noun tasks. The analysis revealed a significant positive correlation for all four pairs, with Pearson's $r$ particularly high for the real noun tasks (Determiner/Real: $r(102)=.69, p<.001$; Adjective/Real: $r(102)=.68$, $p<.001$; Determiner/Novel: $r(102)=.58, p<.001$; Adjective/Novel: $r(102)=.51$, $p<.001)$. With regard to real nouns, the Greek vocabulary scores of our bilinguals appear to explain $47.5 \%$ of the variability in the gender assignment task and $47 \%$ in the gender agreement task. As expected, these percentages drop in the novel noun correlations; specifically, the vocabulary scores appear to explain $34 \%$ of the variability in the assignment task and $26 \%$ in the agreement task.

\subsection{Predictors of gender accuracy}

A stepwise regression analysis ${ }^{11}$ was performed on all experimental variables in order to test for significant predictor variables of the dependent variable, i.e. gender

11. Lack of collinearity issues in our data, as confirmed by diagnostic tests conducted prior to the regression analysis, allowed us to proceed with the stepwise method. Note that a stepwise linear regression is a method of regressing multiple variables while simultaneously removing those that are not important and the variables finally selected explain the distribution best. 
accuracy in gender assignment and agreement tasks. The variables that entered the analysis were Age of Onset of first exposure to Greek, Language Dominance (as measured by vocabulary dominance), Home Language - Greek, Early Literacy Greek, Current Literacy - Greek, Current Language Use - Greek, Mother's SES (Educational Background), Area of residence (Greece or Abroad) and Hours of Instruction in Greek.

Starting with gender assignment to real nouns, the resulting model (adjusted $\left.R^{2}=.428, F(4,98)=11.610, p<.001\right)$ explains $65.4 \%$ of the variance and includes Home Language, Area of Residence, Mother's SES and Current Language Use as significant predictors of gender accuracy (Home Language: $\beta=.350$, $p=.009$, Tolerance $=0.550, \mathrm{VIF}=1.817$, sr:.325; ${ }^{12}$ Area: $\beta=-.621, p<.001$, Tolerance $=0.546, \mathrm{VIF}=1.832, s r:-.518$; Mother's SES: $\beta=-.341, p=.002=8$, Tolerance $=0.594, \mathrm{VIF}=1.684, s r:-.328$; Current Language Use: $\beta=.339, p=.011$, Tolerance $=0.551, \mathrm{VIF}=1.814, s r: .316$ ). Home language (i.e. the amount of Greek at home from birth up to the age of 6) can predict performance on gender assignment on real nouns in that the higher the frequency of use of Greek as a home language in the early years, the higher the accuracy in the task. Similarly, the bilinguals who reside in Greece along with the ones that use Greek frequently for oral daily activities appear to have a better performance in the gender assignment tasks for real nouns but quite unexpectedly, when mother's SES drops the bilingual's accuracy scores in the same task increases.

With regard to gender agreement with real nouns, the resulting model (adjusted $\left.R^{2}=.315, F(3,99)=11.099, p<.001\right)$ explains $58.8 \%$ of the variance and includes Current Language Use of Greek, Area of Residence and Mother's SES as significant predictors of gender accuracy (Current Language Use: $\beta=.496$, $p<.001$, Tolerance $=0.807, \mathrm{VIF}=1.239$, sr:.483; Area: $\beta=-.632, p<.001$, Tolerance $=0.555, \mathrm{VIF}=1.802, s r:-.503$; Mother's SES: $\beta=-.366, p=.007$, Tolerance $=0.598, \mathrm{VIF}=1.671, s r:-.331)$. The current oral use of Greek predicts accuracy in gender agreement with real nouns in that the higher the frequency of use of Greek, the higher the accuracy in the agreement task. Similarly to the resulting model for the real noun gender assignment task, the bilinguals who reside in Greece appear to perform better and the mother's lower SES boosts the bilingual's accuracy scores for real nouns in Greek gender agreement.

Turning to gender assignment for novel nouns, the resulting model (adjusted $\left.R^{2}=.280, F(4,98)=7.412, p<.001\right)$ explains $56.9 \%$ of the variance and includes Home Language, Area of Residence, Early Literacy and Mother's SES as significant predictors of gender accuracy (Home Language: $\beta=.328$,

12. Partial correlation scores $(s r)$ show the individual contribution of each independent variable to the overall variance irrespective of the variance shared with other variables. 
$p=.013$, Tolerance $=0.668, \quad$ VIF $=1.496$, sr..310; Area: $\beta=-.562, p<.001$, Tolerance $=0.537, \mathrm{VIF}=1.863$, sr:-.448; Early Literacy: $\beta=.299, p=.021$, Tolerance $=0.688, \quad \mathrm{VIF}=1.453$, sr:.289; Mother's SES: $\beta=-.302, \quad p=.030$, Tolerance $=0.595$, VIF $=1.682$, sr: -.272 ). The amount of Greek language exposure from birth up to the age of 6 at home along with early literacy exposure to Greek in the pre-school age can positively predict the performance on novel noun gender assignment in that the higher the frequency of use of Greek in the early years, the higher the accuracy in the task. Meanwhile, the bilinguals who reside in Greece appear to perform better and the mother's lower SES boosts the bilingual's accuracy scores similarly to the real noun tasks.

Lastly, with regard to gender agreement in novel nouns, the resulting model (adjusted $R^{2}=.320, F(4,98)=8.781, p<.001$ ) explains $60.1 \%$ of the variance and includes Area of Residence, Early Literacy, Mother's SES and Hours of Greek Instruction as significant predictors of gender accuracy (Area: $\beta=-.946, p<.001$, Tolerance $=0.346$, VIF $=2.890$, sr:-.571; Early Literacy: $\beta=.279, \quad p=.020$, Tolerance $=0.753, \quad$ VIF $=1.328$, sr..242; Mother's SES: $\beta=-.380, p=.005$, Tolerance $=0.604$, VIF $=1.656$, sr: -.346 ; Hours of Greek: $\beta=.352, p=.031$, Tolerance $=0.404, \mathrm{VIF}=2.478, s r: 269$ ). The resulting regression model reveals that (a) bilinguals who reside in Greece appear to perform better, (b) bilinguals that are exposed to literacy in Greek in the pre-school age perform better, (c) the more hours of instruction in Greek a bilingual receives the higher the accuracy scores in novel noun gender agreement and (d) similarly to the real noun assignment and agreement tasks, and the novel noun assignment task, the mother's higher SES negatively affects the bilingual's performance in novel noun gender agreement.

In order to clarify the unexpected role of maternal SES, we further examined its relation to proficiency measures (in both languages) and the rest of the input measures. Note that the overall maternal SES of our participants is quite high and corresponds to that of university education and, thus, the differences discussed refer to a very high SES background (Mean: 4.35, SD: 1.08). Although the Greek vocabulary score did not correlate with mother's SES, the vocabulary scores in the other language (English/German), revealed a correlation. Specifically, the higher the mother's SES the higher the vocabulary development in the other language $(r(102)=.41, p<.001)$. Additionally, when examining the role of maternal SES in the age of onset of exposure to Greek, we found that the higher the SES, the earlier the exposure to both languages $(r(102)=.39, p<.001)$. Turning to Greek input measures, the correlations revealed an overall drop in the amount of Greek input a bilingual receives when living in a high SES environment (Home Language: $r(102)=-.36, p=.003$; Early Literacy: $r(102)=-.29, p=.015$; Current Literacy: $r(102)=-.52, p<.001$; Current Language Use: $r(102)=-.34, p=.004)$. A similar drop is found in the hours of instruction in Greek they receive in the school 
context $(r(102)=-.40, p<.001)$. These findings suggest that within high SES environments, the English-Greek and German-Greek bilinguals tend to be raised as simultaneous bilinguals with a high proficiency level in German and English and reduced Greek input which explains the lower scores in gender accuracy. This finding is not unexpected given that the participants recruited were educated primarily in private schools with a strong preference for developing German or English, respectively for the German-Greek and the English-Greek group.

\section{Discussion}

The study's main objectives were to examine the role of gender in the bilingual's other language on accuracy scores in Greek gender assignment and agreement tasks, along with the role of language proficiency and input in the Greek gender assignment and agreement with real and novel nouns by bilingual children. Both the real and the novel noun data in the gender assignment and gender agreement tasks revealed a strong but expected bilingualism effect with monolinguals outperforming both bilingual groups. Although, gender is acquired early in monolinguals (e.g. Stephany, 1997; Marinis, 2003; Mastropavlou, 2006; Stephany \& Christofidou, 2008), sustained exposure to Greek appears to be important in bilingual development.

We predicted (unidirectional) crosslinguistic influence from German to Greek in the gender performance of bilinguals. Specifically, since German encodes grammatical gender (Bauch, 1971) but English does not, we expected that German-Greek bilinguals would perform better on Greek gender assignment and agreement tasks compared to English-Greek bilinguals. Our findings support this prediction, as the German-Greek bilinguals outperformed the English-Greek bilinguals particularly in the gender assignment tasks. Crucially, even though there was variability in the profile of our bilinguals, when we measured language dominance on the basis of their vocabulary skills in German and Greek, and in English and Greek respectively, no differences were found between the two groups. This allowed us to proceed with the analysis of L1 effects on gender accuracy. Variability in the dataset was further controlled by including the Greek vocabulary measure as a covariate in all between group comparisons.

The higher performance of German-Greek bilinguals compared to the English-Greek group was thus confirmed when we controlled for language proficiency scores in gender assignment both in real and novel nouns but not for gender agreement; specifically, in novel noun gender agreement both groups performed similarly. This indicates that by reducing variability in vocabulary skills positive crosslinguistic influence from the grammatical-gender language (German) particularly in the novel noun data remains evident for gender assignment. Although 
clarifying the precise nature of the L1 effect would require online tasks tapping into the process of the influence itself, our data suggest that the positive crosslinguistic influence in the case of German-Greek children could be based on the shared lexical and morphosyntactic properties of [gender] in both languages. Specifically, gender being a lexical feature on each noun guides the learner in lexical acquisition in both German and Greek.

In addition, the fact that both languages have a tripartite gender system with specific gender values being associated with morpho-phonological cues acting probabilistically in the process of language development are also common resources used and therefore available to transfer successfully. Finally, both Greek and German instantiate gender on determiners and modifiers, albeit syncretically with case and number features. Although some of these cues may be more or less used in a particular task of gender assignment and agreement, we suggest that these similarities are sufficiently strong to allow the bilingual child to draw on the implicit shared properties and the learning strategies that facilitate looking for cues when performing a gender task.

Crucially, what our data suggest is that the positive crosslinguistic influence found seems to be across rather than for each particular gender value. If L1 effects were relevant to particular gender values we would expect performance on neuter in German-Greek bilinguals to be the lowest since neuter has been shown to be delayed in monolingual acquisition of German in comparison to masculine and feminine (see Müller, 1987; Müller 1990; Jansen 2009; Eichler et al., 2012), in contrast to Greek, where neuter is the default and the earliest acquisition in different populations of learners (see Varlokosta, 1995; Tsimpli, 2003; Mastropavlou, 2006; Konta, 2013; Tsimpli \& Hulk, 2013). In our data, German-Greek bilingual children show either higher or similar accuracy in neuter gender compared to masculine nouns. Our findings are similar to results from other studies on German-Italian bilingual children (e.g. Kupisch, 2005; Kupisch, 2007), which showed that positive crosslinguistic influence from Italian to German facilitated the acquisition of gender marking on determiners in German.

Focusing further on gender effects in the performance of all groups, there were additional qualitative differences found in the tasks. Gender assignment showed a significant gender effect with neuter and masculine being treated similarly and with better performance compared to feminine. In the gender agreement tasks, on the other hand, neuter and masculine are discriminated since the former shows significantly better scores compared to masculine and feminine shows the lowest performance. Note also that both bilingual groups performed similarly in the gender agreement tasks and were significantly more accurate with neuter than with masculine and feminine suggesting that neuter is treated as the default value, giving rise to fewer errors. 
Turning to the role of lexical ability on gender accuracy with real and novel nouns, our results revealed a strong interaction between the bilinguals' performance on gender and their Greek vocabulary development, albeit of different strength with real vs. novel nouns. Specifically, Greek vocabulary scores correlated more strongly with gender marking on real nouns than on novel nouns, in both the gender assignment and gender agreement tasks. Overall, half of the variability in our real noun data is explained by vocabulary development; this finding highlights the close interaction between lexical skills and gender. As discussed earlier, this pattern is expected, since gender specification is part of the lexical entry for real nouns, whereas gender on novel nouns is primarily determined on the basis of cues on the noun ending. This pattern has not been identified in the literature before and is one of the main contributions of the present study.

This study also investigates the role of different Greek input factors in gender accuracy in the German-Greek and English-Greek bilingual groups. In line with Gathercole (2002b), Gathercole \& Thomas (2005), Montrul \& Potowski (2007), Unsworth et al. (2011) and Unsworth (2013), we predicted that current exposure to and use of Greek are better predictors of gender accuracy than other input variables, such as age of onset of exposure to Greek and early literacy exposure. These studies also highlighted that it is not the amount of input in the early years but the current amount of input and input over time that appear to affect the development of grammatical gender. The regression analysis of our data supports these predictions. The real noun data showed that the higher the frequency of use of Greek early in life (home practices from birth up to the age of 6) the better the performance; also, bilinguals living in Greece benefited significantly in gender development. Quite unexpectedly, the lower the mother's SES (educational background) the higher the bilinguals' accuracy scores in real noun gender assignment. Additionally, current oral input and use of Greek was shown to be a significant predictor for gender development in real nouns. The real noun gender agreement data showed the same pattern the only difference being that the frequency of use of Greek early in life (Home Language) was not a predictor.

Turning to the novel nouns gender assignment data, the predictors of performance appeared to be Home Language, Area of residence, Early Literacy exposure and maternal SES (educational background). The predictors are partially similar to real nouns but instead of oral language use being of importance it appears that early literacy exposure during the pre-school age is key for the development of the probabilistic values of noun gender endings. This is presumably due to the higher diversity of lexical items, and by extension, nouns which written language is known to be offering in comparison to oral language (Hayes \& Ahrens, 1988; Stanovic \& Cunningham, 1993). This increase in the quality of input would allow bilingual children to generalize across nouns perhaps faster compared to those 
children with lower early literacy exposure to Greek. The novel noun gender agreement data showed Area of residence, Early Literacy exposure, maternal education and the hours of Greek schooling as major predictors. Similarly to the novel noun gender assignment data, literacy measures as indicated via early literacy exposure and school practices appear to be fundamental to gender development in novel nouns. While early literacy seems to increase oral exposure to higher diversity of nouns early on for the bilingual child, school practices can consolidate and increase the mapping between noun endings and gender values because spelling distinctions offer unambiguous evidence for an orally ambiguous cue (Mastropavlou $\&$ Tsimpli, 2011). For example in the case of the $-i$ ending found in a variety of noun declensions of all genders, orthographic conventions which are regular and morphologically driven, can unambiguously serve as cues to the gender of the noun (e.g. $-\eta$ for feminine singular and $-\iota$ for neuter singular).

Overall, in the literature of gender acquisition and more generally, grammatical development, input is identified as key to explaining patterns, delays and vulnerabilities (see Gathercole, 2002b; Jia \& Fuse, 2007; Chondrogianni \& Marinis, 2011). In particular, home language input has been reported to have a positive effect in bilingual language development (De Houwer, 2007; La Morgia, 2011). Nevertheless, the distinction between different measures of input quantity and the boundaries between quantity and quality of input are still open questions. In the present study we contribute to this discussion by distinguishing between different types of input (home, school, oral language vs. literacy practices in preschool and school age). Similarly to the findings of previous studies, our data show that home language practices from birth up to the age of 6 do affect gender development and primarily on real nouns. Furthermore, our findings suggest that different types of input appear to influence accuracy on gender performance in different tasks, with novel nouns being more affected by early literacy and later school practices while real nouns by home language use in preschool age.

However, age of onset of exposure to the second (in order of acquisition) language did not appear to affect the development of gender in our data. Even though the two bilingual groups we examined initially appeared to differ significantly with regard to their distribution in simultaneous and sequential types, this did not appear to affect their performance. Meisel (2009) and Unsworth et al. (2014) report that simultaneous bilinguals perform better compared to sequential bilinguals in gender tasks for real nouns; however, this was not verified in our dataset. One of the reasons this could be the case is that the bilingual children we tested are older compared to the bilinguals tested in these studies and have been exposed to input from written language in instruction settings too. Hence, in our case their age and experience facilitated their development of gender marking. 
Our findings in relation to the role of high maternal education (SES) on lower performance in the gender tasks do not mirror earlier studies (e.g. Calvo \& Bialystok, 2014; Lindholm-Leary, 2014). We attribute this difference to the fact that earlier studies have focused mainly on low SES backgrounds while our participants were of a high SES background, corresponding to college/university education, with an interest in developing both languages from an early age. Furthermore, the positive correlation of SES with the vocabulary proficiency on English and German for each bilingual group respectively provides further support to the suggestion that Greek was less used as a result of the cost of a better balance in bilingualism

\section{Conclusion}

To conclude, we presented a cross-sectional study testing the role of vocabulary skills, L1 influence and input measures in the production of gender assignment and agreement with real and novel nouns. The findings revealed positive L1 influence from German, a gendered language, to Greek. Vocabulary skills (in the tested language) as a measure of proficiency were strongly correlated with performance on real nouns and less so with performance on novel nouns. Meanwhile, vocabulary dominance (as in vocabulary distance between L1 and L2) did not appear to be a predictor factor for gender accuracy in the regression analysis. Crucially, by including different types of input (oral and written input measures) in our data analysis we have managed to tap into different types of input influencing gender accuracy differently in real and novel nouns. The distinction among types of input measures for different tasks is particularly clear in our findings where the role of home language, current language use practices, majority language of the community and family SES are key predictors of performance for real nouns while the role of early literacy and later school skills are the main predictors of gender accuracy scores for novel words. Lastly, this study contributes to questions left open from earlier studies concerning the interaction between input types, vocabulary development and crosslinguistic effects in gender accuracy in Greek. Specifically, the research outcomes of the present study underline how interrelated all these factors are and how they each contribute to the development of a grammatical property, namely gender. Limitations of the study may apply since profiling bilingual speakers is a challenge itself given the extensive variability among them. Nevertheless, the in-depth investigation of profile differences focusing on different input measures when addressing the development of grammatical and lexical properties is shown to be more informative than previously considered. 


\section{Acknowledgements}

This work was supported by the European Union (European Social Fund - ESF) and the Greek national funds through the Operational Program "Education and Lifelong Learning" of the National Strategic Reference Framework (NSRF) - Research Funding Program: Thales. Investing in knowledge society through the European Social Fund [Thales FP7 Project "Bilingual Acquisition \& Bilingual Education: The Development of Linguistic \& Cognitive Abilities in Different Types of Bilingualism" (BALED), Award No 85514 - MIS377313, PI: Ianthi Maria Tsimpli].

\section{Appendix 1. Task items}

Real nouns: Practice items

\begin{tabular}{|c|c|c|c|c|c|c|c|}
\hline \multicolumn{2}{|l|}{ asterias } & \multicolumn{2}{|c|}{ mpala } & \multicolumn{3}{|c|}{ dahtilidi } & \\
\hline \multicolumn{2}{|c|}{ starfish $_{\text {MASC }}$} & \multicolumn{2}{|c|}{ ball $_{\mathrm{FEM}}$} & \multicolumn{3}{|c|}{$\operatorname{ring}_{\mathrm{NEUT}}$} & \\
\hline \multicolumn{2}{|l|}{ 'Starfish' } & \multicolumn{2}{|c|}{ 'Ball' } & \multicolumn{3}{|c|}{ 'Ring' } & \\
\hline \multicolumn{8}{|c|}{ Real nouns: Test items } \\
\hline Masculine & & & Feminine & & Neuter & & \\
\hline$\frac{- \text { as }}{\text { kokoras }}$ & $\frac{-\mathrm{os}}{\text { papagalos }}$ & $\frac{- \text { is }}{\text { planitis }}$ & $\frac{-\mathbf{i}}{\text { klosti }}$ & $\frac{\text {-a }}{\text { petalouda }}$ & $\frac{-\mathbf{i}}{\text { delfini }}$ & $\frac{-\mathrm{ma}}{\text { kima }}$ & $\begin{array}{l}\underline{-0} \\
\text { pagoto }\end{array}$ \\
\hline $\begin{array}{l}\text { 'Rooster' } \\
\text { karharias }\end{array}$ & $\begin{array}{l}\text { 'Parrot' } \\
\text { likos }\end{array}$ & $\begin{array}{l}\text { 'Planet' } \\
\text { ipologistis }\end{array}$ & $\begin{array}{l}\text { 'Thread' } \\
\text { astrapi }\end{array}$ & $\begin{array}{l}\text { 'Butterfly' } \\
\text { arkouda }\end{array}$ & $\begin{array}{l}\text { 'Dolphin' } \\
\text { psomi }\end{array}$ & $\begin{array}{l}\text { 'Wave' } \\
\text { grama }\end{array}$ & $\begin{array}{l}\text { 'Ice cream' } \\
\text { piato }\end{array}$ \\
\hline $\begin{array}{l}\text { 'Shark' } \\
\text { elefantas }\end{array}$ & $\begin{array}{l}\text { 'Wolf' } \\
\text { lagos }\end{array}$ & $\begin{array}{l}\text { 'Computer' } \\
\text { magnitis }\end{array}$ & $\begin{array}{l}\text { 'Lightning' } \\
\text { zoni }\end{array}$ & $\begin{array}{l}\text { 'Bear' } \\
\text { kamila }\end{array}$ & $\begin{array}{l}\text { 'Bread' } \\
\text { pontiki }\end{array}$ & $\begin{array}{l}\text { 'Letter' } \\
\text { dema }\end{array}$ & $\begin{array}{l}\text { 'Plate' } \\
\text { dentro }\end{array}$ \\
\hline $\begin{array}{l}\text { 'Elephant' } \\
\text { gorilas }\end{array}$ & $\begin{array}{l}\text { 'Hare' } \\
\text { vatrahos }\end{array}$ & $\begin{array}{l}\text { 'Magnet' } \\
\text { kathreftis }\end{array}$ & $\begin{array}{l}\text { 'Belt' } \\
\text { zimi }\end{array}$ & $\begin{array}{l}\text { 'Camel' } \\
\text { karekla }\end{array}$ & $\begin{array}{l}\text { 'Mouse' } \\
\text { krevati }\end{array}$ & $\begin{array}{l}\text { 'Parcel' } \\
\text { stema }\end{array}$ & $\begin{array}{l}\text { 'Tree' } \\
\text { podilato }\end{array}$ \\
\hline $\begin{array}{l}\text { 'Gorilla' } \\
\text { harakas }\end{array}$ & $\begin{array}{l}\text { 'Frog' } \\
\text { pigouinos }\end{array}$ & $\begin{array}{l}\text { 'Mirror' } \\
\text { diavitis }\end{array}$ & $\begin{array}{l}\text { 'Dough' } \\
\text { arahni }\end{array}$ & $\begin{array}{l}\text { 'Chair’ } \\
\text { katsika }\end{array}$ & $\begin{array}{l}\text { 'Bed' } \\
\text { louloudi }\end{array}$ & $\begin{array}{l}\text { 'Crown' } \\
\text { aroma }\end{array}$ & $\begin{array}{l}\text { 'Bicycle' } \\
\text { alogo }\end{array}$ \\
\hline $\begin{array}{l}\text { 'Ruler' } \\
\text { pinakas }\end{array}$ & $\begin{array}{l}\text { 'Penguin' } \\
\text { kiknos }\end{array}$ & $\begin{array}{l}\text { 'Compass' } \\
\text { hartis }\end{array}$ & $\begin{array}{l}\text { 'Spider' } \\
\text { poli }\end{array}$ & $\begin{array}{l}\text { 'Goat' } \\
\text { kota }\end{array}$ & $\begin{array}{l}\text { 'Flower' } \\
\text { liontari }\end{array}$ & $\begin{array}{l}\text { 'Perfume' } \\
\text { nomisma }\end{array}$ & $\begin{array}{l}\text { 'Horse' } \\
\text { vivlio }\end{array}$ \\
\hline 'Board' & 'Swan' & 'Map' & $\begin{array}{l}\text { 'City' } \\
\text { tileorasi } \\
\text { 'Television' } \\
\text { stoli } \\
\text { 'Uniform' } \\
\text { tigri } \\
\text { 'Tiger' }\end{array}$ & $\begin{array}{l}\text { 'Hen' } \\
\text { agelada } \\
\text { 'Cow' } \\
\text { melissa } \\
\text { 'Bee' } \\
\text { papia } \\
\text { 'Duck' }\end{array}$ & 'Lion' & ‘Coin’ & 'Book' \\
\hline
\end{tabular}

Novel nouns: Practice items

\begin{tabular}{lll}
\hline pigantas & kineka & kolivi \\
\hline pigantas $_{\text {MASC }}$ & kineka $_{\mathrm{FEM}}$ & kolivi $_{\text {NEUT }}$ \\
\hline
\end{tabular}


Novel nouns: Test items

\begin{tabular}{lllllll}
\hline Masculine & & \multicolumn{3}{c}{ Feminine } & Neuter \\
\hline$\underline{\text {-as }}$ & $\underline{- \text { os }}$ & $\underline{-\mathbf{i s}}$ & $\underline{-\mathbf{i}}$ & $\underline{\underline{-a}}$ & $\underline{\underline{-m a}}$ & $\underline{\underline{-0}}$ \\
hlitiras & sfeletos & krodotis & gratisi & traoula & katoma & franio \\
panonas & ploskopos & tranitis & penisi & vrateza & krovlima & melino \\
kilakas & sviouros & skanitis & mekani & stantalia & klipima & krosopo \\
krastiras & htistianos & flelalis & spihani & prompeta & lathima & klaouto \\
trakoulas & klitikos & pathitis & stektani & spafida & flenema & klafio \\
drofeas & gratanos & skourgitis & ftegasi & floutiera & skadema & kotsalo \\
fratiras & paskalos & vrofitis & sferisi & kitera & vrohisma & vrigono \\
skasiklas & pografos & kolitis & flotasi & parekla & plothema & vranio \\
\hline
\end{tabular}

\section{Appendix 2. ANCOVA analysis}

\section{Total Accuracy Scores for Gender Assignment}

Within group: word (real vs. novel)

Between group: group (English-Greek bilinguals vs. German-Greek bilinguals vs. Greek monolinguals)

Covariate: language proficiency (Greek vocabulary score)

\begin{tabular}{ll}
\hline Word & $F(1,133)=7.54, p=.007, \eta_{\mathrm{p}}{ }^{2}=.054$ \\
& real $>$ novel: $p<.001$ \\
Group & $F(2,<133)=13.45, p<.001, \eta_{\mathrm{p}}{ }^{2}=.168$ \\
& English-Greek bilinguals $<$ Monolinguals: $p<.001$ \\
& German-Greek bilinguals $=$ Monolinguals: $p=.812$ \\
& English-Greek bilinguals $<$ German-Greek bilinguals: $p<.001$ \\
Word ${ }^{*}$ Group & $F(2,133)=4.48, p=.013, \eta_{\mathrm{p}}{ }^{2}=.063$ \\
\hline
\end{tabular}

\section{Total Accuracy Scores for Gender Agreement}

Within group: word (real vs. novel)

Between group: group (English-Greek bilinguals vs. German-Greek bilinguals vs. Greek monolinguals)

Covariate: language proficiency (Greek vocabulary score)

\begin{tabular}{ll}
\hline Word & $F(1,133)=10.39, p=.002, \eta_{\mathrm{p}}{ }^{2}=.072$ \\
& real $>$ novel: $p<.001$ \\
Group & $F(2,133)=3.51, p=.033, \eta_{\mathrm{p}}{ }^{2}=.050$ \\
& Monolinguals $>$ English-Greek bilinguals: $p=.005$ \\
& Monolinguals $>$ German-Greek bilinguals: $p=.012$ \\
& German-Greek bilinguals $=$ Monolinguals: $p=.098$ \\
Word ${ }^{*}$ Group & $F(2,133)=4.54, p=.012, \eta_{\mathrm{p}}{ }^{2}=.064$ \\
\hline
\end{tabular}




\section{Accuracy Scores per Gender for Gender Assignment}

Within group: gender (masculine vs. feminine vs. neuter), word (real vs. novel)

Between group: group (English-Greek bilinguals vs. German-Greek bilinguals vs. Greek monolinguals)

Covariate: language proficiency (Greek vocabulary score)

\begin{tabular}{ll}
\hline Gender & $F(2,133)=60.63, p<.001, \eta_{\mathrm{p}}{ }^{2}=.313$ \\
& masculine $>$ feminine: $p<.001$ \\
& neuter $>$ feminine: $p<.001$ \\
& masculine $=$ neuter: $p=1.000$ \\
Gender ${ }^{\star}$ Group & $F(2,133)=5.62, p=.005, \eta_{\mathrm{p}}{ }^{2}=.078$ \\
Word & $F(1,133)=4.01, p=.047, \eta_{\mathrm{p}}{ }^{2}=.029$ \\
& real $>$ novel: $p<.001$ \\
Word ${ }^{*}$ Group & $F(2,133)=1.21, p=.299, \eta_{\mathrm{p}}{ }^{2}=.018$ \\
Gender ${ }^{\star}$ Word & $F(1,133)=1.28, p=.259, \eta_{\mathrm{p}}{ }^{2}=.010$ \\
Gender ${ }^{\star}$ Word ${ }^{*}$ Group & $F(2,133)=.18, p=.899, \eta_{\mathrm{p}}{ }^{2}=.003$ \\
\hline
\end{tabular}

\section{Accuracy Scores per Gender for Gender Agreement}

Within group: gender (masculine vs. feminine vs. neuter), word (real vs. novel)

Between group: group (English-Greek bilinguals vs. German-Greek bilinguals vs. Greek monolinguals)

Covariate: language proficiency (Greek vocabulary score)

\begin{tabular}{ll}
\hline Gender & $F(2,133)=117.42, p<.001, \eta_{\mathrm{p}}{ }^{2}=.469$ \\
& masculine $>$ feminine: $p<.001$ \\
& masculine $>$ neuter: $p<.001$ \\
& neuter $>$ feminine: $p<.001$ \\
& $F(2,133)=3.96, p=.021, \eta_{\mathrm{p}}{ }^{2}=.056$ \\
Gender ${ }^{\star}$ Group & $F(1,133)=5.10, p=.025, \eta_{\mathrm{p}}{ }^{2}=.037$ \\
Word & real $>$ novel: $p<.001$ \\
& $F(2,133)=7.11, p=.001, \eta_{\mathrm{p}}{ }^{2}=.097$ \\
Word ${ }^{\star}$ Group & $F(1,133)=9.50, p=.002, \eta_{\mathrm{p}}{ }^{2}=.067$ \\
Gender ${ }^{\star}$ Word & $F(2,133)=.71, p=.490, \eta_{\mathrm{p}}{ }^{2}=.011$ \\
Gender ${ }^{\star}$ Word ${ }^{*}$ Group &
\end{tabular}

\section{References}

Argyri, F., \& Sorace, A. (2007). Crosslinguistic influence and language dominance in older bilingual children. Bilingualism: Language and Cognition, 10, 79-99. doi: $10.1017 / S 1366728906002835$

Armon-Lotem, S., Walters, J., \& Gagarina, N. (2011). The impact of internal and external factors on linguistic performance in the home language and in L2 among Russian - Hebrew and 
Russian - German preschool children. Linguistic Approaches to Bilingualism, 1, 291-317. doi: 10.1075/lab.1.3.04arm

Bauch, H. J. (1971). Zum Informationsgehalt der Kategorie Genus im Deutschen, Englischen und Polnischen. Wissenschaftliche Zeitschrift Der Universität Rostock: Gesellschafts-und Sprachwissenschaftliche Reihe, 20(6), 411-419.

Blair, C., Granger, D. A., Willoughby, M., Mills-Koonce, R., Cox, M., Greenberg, M. T., Kivlighan, K. T. \& Fortunato, C. K. (2011). Salivary cortisol mediates effects of poverty and parenting on executive functions in early childhood. Child Development, 82(6), 1970-1984. doi: 10.1111/j.1467-8624.2011.01643.x

Bialystok, E. (2001). Bilingualism in development: Language, literacy, and cognition. Cambridge University Press. doi: 10.1017/CBO9780511605963

Blom, E., Polišenská, D., \& Weerman, F. (2008). Articles, adjectives and age of onset: The acquisition of Dutch grammatical gender. Second Language Research, 24(3), 297-331. doi: $10.1177 / 0267658308090183$

Blom, E. (2010). Effects of input on the early grammatical development of bilingual children. International Journal of Bilingualism, 14, 422-446. doi: 10.1177/1367006910370917

Bloomfield, L. (1933). Language. New York: Holt, Rinehart and Winston.

Bošković, Z. (2009a). Unifying first and last conjunct agreement. Natural Language and Linguistic Theory, 27(3), 455-496. doi: 10.1007/s11049-009-9072-6

Bošković, Z. (2009b). On valued uninterpretable features. In: Proceedings of NELS 39, Cornell.

Bradley, R. H., \& Corwyn, R. F. (2002). Socioeconomic status and child development. Annual Review of Psychology, 53(1), 371-399. doi: 10.1146/annurev.psych.53.100901.135233

Calvo, A., \& Bialystok, E. (2014). Independent effects of bilingualism and socioeconomic status on language ability and executive functioning. Cognition, 130(3), 278-288. doi: 10.1016/j.cognition.2013.11.015

Cantone, K., Kupisch, T., Müller, N., \& Schmitz, K. (2008). Rethinking language dominance in bilingual children. Linguistische Berichte, 215, 307-343.

Carroll, S. E. (1989). Second-language acquisition and the computational paradigm. Language Learning, 39, 535-594. doi: 10.1111/j.1467-1770.1989.tboo902.x

Carstens, V. (2000). Concord in minimalist theory. Linguistic Inquiry, 31, 319-355. doi: 10.1162/002438900554370

Chomsky, N. (1995). The Minimalist Program. The MIT Press, Cambridge, MA.

Chomsky, N. (2001). Derivation by phase. In: Kenstovicz, M. (Ed.), Ken Hale: A Life in Language. The MIT Press, Cambridge, MA, pp. 1-54.

Chondrogianni, V., \& Marinis, T. (2011). Differential effects of internal and external factors on the development of vocabulary, tense morphology, and morphosyntax in successive bilingual children. Linguistic Approaches to Bilingualism, 1, 318-342. doi: 10.1075/lab.1.3.05cho

Cohen, J. (1988). Statistical power analysis for the behavioral sciences. Hillsdale, NJ: Lawrence Erlbaum Associates.

Cobo-Lewis, A. B., Pearson, B. Z., Eilers, R. E., \& Umbel, V. C. (2002). Effects of bilingualism and bilingual education on oral and written Spanish skills: A multifactor study of standardized test outcomes. In D. K. Oller and R. E. Eilers (Eds.), Language and literacy in bilingual children. Clevedon: Multilingual Matters.

Corbett, G. (1991). Gender. Cambridge: Cambridge University Press. doi: $10.1017 / C B O 9781139166119$

Cornips, L., \& Hulk, A. (2006). External and internal factors in bilingual and bidialectal language development: Grammatical gender of the Dutch definite determiner. In C. Lefebvre, 
L. White, and C. Jourdan (Eds.), L2 acquisition and creole genesis: Dialogues. Amsterdam: John Benjamins. doi: 10.1075/lald.42.21cor

De Houwer, A. (1990). The acquisition of two languages from birth: A case study. Cambridge University Press.

De Houwer, A. (2007). Parental language input patterns and children's bilingual use. Applied Psycholinguistics, 28, 411-424. doi: 10.1017/S0142716407070221

Döpke, S. (1998). Competing language structures: The acquisition of verb placement by bilingual German-English children. Journal of child language, 25(3), 555-584.

Eichler, N., Jansen, V., \& Müller, N. (2012). Gender acquisition in bilingual children: French German, Italian - German, Spanish - German and Italian - French. International Journal of Bilingualism, 17(5), 550-570. doi: 10.1177/1367006911435719

Featherston, S., \& Winkler, S. (Eds.). (2009). The Fruits of Empirical Linguistics 1: Process (Vol. 101). Walter de Gruyter. doi: $10.1515 / 9783110216141$

Gathercole, V. C. M. (2002a). Command of the mass/count distinction in bilingual and monolingual children: An English morphosyntactic distinction. In D. K. Oller and R. E. Eilers (Eds.), Language and literacy in bilingual children. Clevedon: Multilingual Matters.

Gathercole, V. C. M. (2002b). Grammatical gender in bilingual and monolingual children: A Spanish morphosyntactic distinction. In D. K. Oller and R. E. Eilers (Eds.), Language and literacy in bilingual children. Clevedon: Multilingual Matters.

Gathercole, V. C. M., \& Thomas, E. M. (2005). Minority language survival: Input factors influencing the acquisition of Welsh. In J. Cohen, K. McAlister, K. Rolstad and J. MacSwan (Eds.), Proceedings of the 4th International Symposium on Bilingualism. Somerville, MA: Cascadilla Press.

Genesee, F., \& Nicoladis, E. (2007). Bilingual first-language acquisition. In E. Hoff and P. McCardle (Eds.), Handbook of language development. Oxford: Blackwell. doi: 10.1002/9780470757833.ch16

Goldberg, H., Paradis, J., \& Crago, M. (2008). Lexical acquisition over time in minority L1 children learning English as L2. Applied Psycholinguistics, 29, 41-65.

Grosjean, F. (1989). Neurolinguists, beware! The bilingual is not two monolinguals in one person. Brain and language, 36(1), 3-15. doi: 10.1016/0093-934X(89)90048-5

Hawkins, R. \& Tsimpli, I. M. (2009). Explaining target- and non-target performance in the acquisition of Gender concord by L2 speakers. Paper presented at ISB7, Utrecht, July 2009.

Hayes, D. P., \& Ahrens, M. G. (1988). Vocabulary simplification for children: A special case of 'motherese'?. Journal of Child Language, 15(02), 395-410. doi: 10.1017/S0305000900012411

Hoeppner, W. (1980). Derivative Wortbildung der deutschen Gegenwartssprache und ihre algorithmische Analyse (Vol. 128). Narr.

Hoff-Ginsberg, E. (1991). Mother-child conversation in different social classes and communicative settings. Child Development, 62(4), 782-796. doi: 10.2307/1131177

Hoff, E. (2006). How social contexts support and shape language development. Developmental review, 26(1), 55-88.

Jansen, V. (2009). Determiners in first language acquisition of monolingual English and German children - A corpus-based investigation (Unpublished master's thesis). Bergische Universität Wuppertal, Germany.

Jia, G., \& Aaronson, D. (2003). A longitudinal study of Chinese children and adolescents learning English in the United States. Applied Psycholinguistics, 24(1), 131-161. 
Jia, G., \& Fuse, A. (2007). Acquisition of English grammatical morphology by native Mandarin speaking children and adolescents: Age-related differences. Journal of Speech, Language, and Hearing Research, 50, 1280-1299. doi: 10.1044/1092-4388(2007/090)

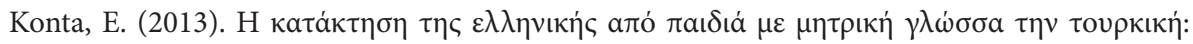

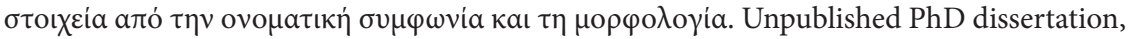
Aristotle University of Thessaloniki. doi: 10.12681/eadd/29880

Köpcke, K. M. (1982). Untersuchungen zum Genussystem der deutschen Gegenwartssprache [Research on the gender system of present-day German]. Tübingen, Germany: Niemeyer. doi: $10.1515 / 9783111676562$

Kuchenbrandt, I. (2005). Gender acquisition in bilingual Spanish. In J. Cohen, K. T. McAlister, K. Rolstad, and J. MacSwan (Eds.) Proceedings of the 4th International Symposium on Bilingualism (ISB4) (pp. 1252-1263). Somerville: Cascadilla Press.

Kupisch, T. (2005). Acceleration in bilingual first language acquisition. In Twan Gaerts, Ivo Van Ginneken and Haike Jacobs (eds.), Languages and Linguistic Theory, Selected Papers from Going Romance 2003. Amsterdam: John Benjamins. pp. 143-157.

doi: $10.1075 /$ cilt.270.09kup

Kupisch, T. (2007). Determiners in Bilingual German-Italian children: what they tell us about the relation between language influence and language dominance. Bilingualism: Language and Cognition 10(1), 75-78. doi: 10.1017/S1366728906002823

Kupisch, T., Müller, N., \& Cantone, K. F. (2002). Gender in monolingual and bilingual firstlanguage acquisition. Lingue e Linguaggio, 1, 107-150.

Kupisch, T., Akpinar, D., \& A. Stöhr. (2013). Gender assignment and gender agreement in adult bilinguals and second language learners of French. Linguistic Approaches to Bilingualism, 3(2), 150-179. doi: 10.1075/lab.3.2.02kup

Lang, A. (1976). The semantic base of gender in German. Lingua, 40(1), 55-68. doi: 10.1016/0024-3841(76)90032-2

La Morgia, F. (2011). Bilingual first-language acquisition: The nature of the weak language and the role of the input. Unpublished PhD dissertation, Dublin City University.

Lindholm-Leary, K. (2014). Bilingual and biliteracy skills in young Spanish-speaking low-SES children: impact of instructional language and primary language proficiency. International Journal of Bilingual Education and Bilingualism, 17(2), 144-159. doi: $10.1080 / 13670050.2013 .866625$

Locke, A., Ginsborg, J., \& Peers, I. (2002). Development and disadvantage: implications for the early years and beyond. International Journal of Language \& Communication Disorders, 37(1), 3-15. doi: 10.1080/13682820110089911

Marinis, T. (2003). The Acquisition of the DP in Modern Greek. Amsterdam: John Benjamins Publishers. doi: $10.1075 /$ lald.31

Mastropavlou, M. (2006). The role of phonological salience and feature interpretability in the grammar of typically developing and language-impaired children. Unpublished $\mathrm{PhD}$ dissertation, Aristotle University of Thessaloniki.

Mastropavlou, M., \& Tsimpli, I. M. (2011). The role of suffixes in grammatical gender assignment in Modern Greek: A psycholinguistic study. Journal of Greek Linguistics, 11, 27-55.

Mattheoudakis, M., Chatzidaki, A. \& Maligkoudi, C. (2014). Bilingual Education \& Types of Bilingualism. In Workshop Language Knowledge and Development in native and non-native speakers. Aristotle University of Thessaloniki, Greece.

Meisel, J. M. (2009). Second-language acquisition in early childhood. Zeitschrift Für Sprachwissenschaft, 28, 5-34. 
Mills, A. E. (1986). Acquisition of the natural-gender rule in English and German. Linguistics, 24(1), 31-46. doi: 10.1515/ling.1986.24.1.31

Montrul, S. A., Foote, R., \& Perpiñán, S. (2008). Gender agreement in adult second-language learners and Spanish-heritage speakers: The effects of age and context of acquisition. Language Learning, 58, 503-553. doi: 10.1111/j.1467-9922.2008.00449.x

Montrul, S., \& Potowski, K. (2007). Command of gender agreement in school-age Spanish English bilingual children. International Journal of Bilingualism, 11, 301-328. doi: $10.1177 / 13670069070110030301$

Montrul, S. A. (2016). Dominance and Profociency in early and late bilingualism. In C. Silva-Corvalan \& J. Treffers-Daller (Eds.) Language Dominance in Bilinguals: Issues of Measurement and Operationalization. Cambridge University Press. 15-35. doi: 10.1017/CBO9781107375345.002

Müller, N. (1987). Der Genuserwerb im Französischen und Deutschen: Eine empirische Untersuchung eines bilingualen Kindes (Unpublished master's thesis). University of Hamburg, Germany.

Müller, N. (1990). Developing two gender-assignment systems simultaneously. In J.M. Meisel (Ed.), Two First Languages: Early Grammatical Development in Bilingual Children. Dordrecht: Foris. doi: 10.1515/9783110846065.193

Müller, N. (1998). Transfer in Bilingual First Language Acquisition. Bilingualism: Language and Cognition 1(3), 151-171. doi: 10.1017/S1366728998000261

Müller, N. \& Hulk, A. (2001). Crosslinguistic Influence in Bilingual Language Acquisition: Italian and French as Recipient Languages. Bilingualism: Language and Cognition 4(1), 1-21. doi: 10.1017/S1366728901000116

Oller, D. K., \& Eilers, R. E. (Eds.). (2002). Language and literacy in bilingual children (Vol. 2). Multilingual Matters.

Paradis, J. (2010). Bilingual children's acquisition of English verb morphology: Effects of language exposure, structure complexity, and task type. Language Learning, 60, 651-680. doi: 10.1111/j.1467-9922.2010.00567.x

Paradis, J. (2011). Individual differences in child English second-language acquisition: Comparing child-internal and child-external factors. Linguistic Approaches to Bilingualism, 1,213-237. doi: 10.1075/lab.1.3.01par

Paradis, J., \& Genesee, F. (1996). Syntactic acquisition in bilingual children: Autonomous or independent? Studies in Second Language Acquisition, 18, 1-25.

doi: $10.1017 /$ So272263100014662

Petermann, F. (2010). SET 5-10. Sprachstandserhebungstest für Kinder im Alter zwischen 5 und 10 Jahren. Göttingen: Hogrefe.

Place, S., \& Hoff, E. (2011). Properties of dual language exposure that influence two-year-olds' bilingual proficiency. Child Development, 82, 1834-1849. doi: 10.1111/j.1467-8624.2011.016 6o.x

Qi, C. H., Kaiser, A. P., Milan, S., \& Hancock, T. (2006). Language performance of low-income African American and European American preschool children on the PPVT - III. Language, Speech, and Hearing Services in Schools, 37(1), 5-16. doi: 10.1044/0161-1461(2006/002)

Ralli, A. (2002). The role of morphology in gender determination: Evidence from Modern Greek. Linguistics, 40, 519-551. doi: 10.1515/ling.2002.022

Renfrew, C. E. (2001). Word Finding Vocabulary Test. 4th Edition. Bicester, UK: Speechmark. 
Rhoades, B. L., Greenberg, M. T., Lanza, S. T., \& Blair, C. (2011). Demographic and familial predictors of early executive function development: Contribution of a person-centered perspective. Journal of Experimental Child Psychology, 108(3), 638-662.

doi: 10.1016/j.jecp.2010.08.004

Silva-Corvalán, C. \& Treffers-Daller, J. (2016). Language Dominance in Bilinguals: Issues of Measurement and Operationalization. Cambridge University Press. doi: $10.1017 / C B O 9781107375345$

Stanovich, K. E., \& Cunningham, A. E. (1993). Where does knowledge come from? Specific associations between print exposure and information acquisition. Journal of Educational Psychology, 85(2), 211. doi: 10.1037/0022-0663.85.2.211

Stephany, U., (1997). The acquisition of Greek. In: Slobin, D. I. (Ed.), The Cross-linguistic Study of Language Acquisition, vol. 4. Erlbaum, Hillsdale, NJ, pp. 183-333.

Stephany, U. \& Christofidou, A. (2008). The Acquisition of Greek Case, Number, and Gender: A Usage-Based Approach. Arbeitspapier 55 (Neue Folge). Allgemeine Sprachwissenschaft, University of Cologne.

Szagun, G., Stumper, B., Sondag, N., \& Franik, M. (2007). The acquisition of gender marking by young German-speaking children: Evidence for learning guided by phonological regularities. Journal of Child Language, 34(03), 445-471. doi: 10.1017/S0305000906007951

Tsimpli, I. M. (2003). Features in L1 and L2 acquisition: Evidence from Greek clitics and determiners. Acquisition et Interaction en Langue Étrangère, 20, 87-128.

Tsimpli, I. M. (2014). Early, late or very late? Timing acquisition and bilingualism. Linguistic Approaches to Bilingualism, 4(3), 283-313. doi: 10.1075/lab.4.3.01tsi

Tsimpli, I. M., \& Hulk, A. (2013). Grammatical gender and the notion of default: Insights from language acquisition. Lingua, 137, 128-144. doi: 10.1016/j.lingua.2013.09.001

Unsworth, S., Argyri, F., Cornips, L., Hulk, A., Sorace, A. \& Tsimpli, I. M. (2011). Bilingual acquisition of Greek voice morphology and Dutch gender: What do they have in common? In N. Danis, K. Mesh \& H. Sung (Eds.), Proceedings of the 35th annual Boston University Conference on Language Development, (pp. 590-602). Somerville, MA: Cascadilla Press.

Unsworth, S. (2013). Assessing the role of current and cumulative exposure in simultaneous bilingual acquisition: The case of Dutch gender. Bilingualism: Language and Cognition, 16, 86-110. doi: $10.1017 / S 1366728912000284$

Unsworth, S., Argyri, F., Cornips, L., Hulk, A., Sorace, A. \& Tsimpli, I. M. (2014). On the role of age of onset and input in early child bilingualism in Greek and Dutch. Applied Psycholinguistics, 34(4), 765-805. doi: 10.1017/S0142716412000574

Unsworth, S. (2016). Amount of exposure as a proxy for dominance in bilingual language acquisition. In C. Silva-Corvalan \& J. Treffers-Daller (Eds.) Language Dominance in Bilinguals: Issues of Measurement and Operationalization. Cambridge University Press. 156-173. doi: 10.1017/CBO9781107375345.008

Varlokosta, S. (1995). Greek as a second language in minority schools of Thrace: Learning gender compared to learning number and case within the NP. Unpublished manuscript.

Varlokosta, S. (2011). The role of morphology in grammatical gender assignment: A psycholinguistic study in Greek. In A. Galani, G. Hicks, and G. Tsoulas (Eds.), Morphology and its interfaces. Amsterdam: John Benjamins Publishing. doi: 10.1075/la.178.17var

Vogindroukas, I., Protopapas, A., \& Sideridis, G. (2009). Experiment on the Expressive Vocabulary (Greek version of Renfrew Word Finding Vocabulary Test). Chania, Crete: Glafki.

Yip, V., \& Matthews, S. (2000). Syntactic transfer in a Cantonese-English bilingual child. Bilingualism: Language and cognition, 3(3), 193-208. 
Yip, V., \& Matthews, S. (2006). Assessing language dominance in bilingual acquisition: A case for mean length utterance differentials. Language Assessment Quarterly: An International Journal, 3(2), 97-116. doi: 10.1207/s15434311laq0302_2

\section{Authors' addresses}

Maria Kaltsa

Faculty of Philosophy

Aristotle University of Thessaloniki

Department of Theoretical \& Applied

Linguistics

Greece

mkaltsa@enl.auth.gr

Ianthi Maria Tsimpli

Faculty of Modern \& Medieval Languages

Department of Theoretical and Applied

Linguistics

University of Cambridge

United Kingdom

imt20@cam.ac.uk

\section{Publication history}

Date received: 4 July 2016

Date accepted: 24 August 2017

Published online: 16 October 2017
Froso Argyri

Division of Psychology and Language

Sciences

Research Department of Linguistics

UCL

United Kingdom

f.argyri@ucl.ac.uk 